\title{
Análise espaço-temporal da ocorrência de sistemas de irrigação por pivô central em regiões agrícolas no estado de Mato Grosso
}

\author{
Edgar Nogueira DEMARQUI ${ }^{1 *}$, Lígia Manccini Barros DEMARQUI ${ }^{1}$
}

\author{
${ }^{1}$ Instituto de Ciências Agrárias e Ambientais, Universidade Federal de Mato Grosso, Sinop, MT, Brasil. \\ (ORCID: 0000-0003-2435-9344; 0000-0001-5405-1741) \\ *E-mail: edgardemarqui@cpd.ufmt.br
}

Recebido em 14/08/2019; Aceito em 19/04/2020; Publicado em 24/04/2020.

\begin{abstract}
RESUMO: A utilização de técnicas de irrigação visando a produção agrícola tem apresentado crescimento nos últimos anos, sendo que o sistema de irrigação por pivô central (PC) também avançou no quantitativo de unidades implantadas e no total de área abrangida. Isto se deve às características desse tipo de sistema, as quais mostram-se vantajosas para o produtor rural, tais como economia de mão-de-obra e facilidade de operação, entre outras. O formato circular deste tipo de sistema facilita sua identificação através de técnicas de Geoprocessamento aplicadas nas análises de imagens orbitais ou aéreas, permitindo análises quantitativas e de espacialização. Neste contexto, o presente trabalho teve como objetivo mapear, por meio de imagens orbitais, as áreas irrigadas por PC no período de 11 anos (2004 a 2015) referente à três regiões que possuem destaque na produção agrícola no Estado de Mato Grosso: Médio Norte, Parecis e Sudeste. A região Médio Norte apresentou taxa média de crescimento anual de 10,96\% na sua área irrigada, a região Sudeste 6,75\% e a região dos Parecis 4,28\%. A evolução média no número de pivôs nestas áreas foi da ordem de 8,07\% ao ano, passando de 259 unidades em 2004, para 586 no ano de 2015, totalizando um crescimento de 226,25\% no período.
\end{abstract}

Palavras-chave: áreas irrigadas; produção agrícola; geoprocessamento; sensoriamento remoto.

\section{Space-temporal analysis of the occurrence of central pivot irrigation systems in agricultural regions in the state of Mato Grosso}

\begin{abstract}
The use of irrigation techniques in agricultural production has increased in the last years, and the center-pivot irrigation system has advanced in number of implanted units. This system, due to its characteristics such as labor savings and ease of operation, has proved to be advantageous for the rural producer. The circular shape of this system allows it to be identified by Geoprocessing techniques applied to the quantitative and spatial analysis of orbital or aerial images. In this context, the present work aimed to map, through orbital images, the center-pivot irrigated areas, for a period of 11 years (2004 to 2015) referring to three regions of Mato Grosso State, witch that stand out in agricultural production: Middle North, Parecis and Southeast. The Middle North region presented an average annual growth rate of $10.96 \%$ in its irrigated area, the Southeast region 6.75\% and the Parecis region 4.28\%. The average evolution in the number of pivots in these areas was of the order of $8.07 \%$ per year, going from 259 units in 2004, to 586 in 2015, totaling a growth of $226.25 \%$ in the period.
\end{abstract}

Keywords: irrigated areas; agricultural production; geoprocessing; remote sensing.

\section{INTRODUÇÃO}

A agricultura irrigada tem grande importância no desenvolvimento da produção mundial de alimentos, pois sua prática promove geração de empregos e renda, assim como o desenvolvimento sustentável no campo (MANTOVANI et al., 2007). Em um cenário mundial em que muitos países já utilizam quase toda área agricultável, observa-se que a agricultura irrigada tem grande potencial produtivo, valor econômico e potencial de expansão para áreas até então não produtivas devido à falta de chuvas.

Sistemas de irrigação por pivô central apresentaram crescimento expressivo nos últimos anos, sendo o sistema com maior expansão no Brasil (MANTOVANI et al., 2007). A irrigação é o principal setor usuário de recursos hídricos em escala mundial (ANA, 2016), sendo importante o seu uso disciplinado pelas legislações ambientais relacionadas ao tema.
Segundo levantamento feito pela ANA e EMBRAPA em 2016, o Estado de Mato Grosso apresentou em 2014 aproximadamente área total irrigada por pivô central de 80 mil hectares. Neste Estado, a irrigação apresenta-se como uma alternativa para a produção agrícola no período de estiagem, visto que o Estado é caracterizado por uma distinção bem definida entre a estação chuvosa e seca.

Atualmente o Geoprocessamento propicia um conjunto de técnicas e ferramentas computacionais que permitem a identificação e quantificação de áreas irrigadas por meio de pivô central, o qual, devido ao formato circular, permite que sua identificação seja facilitada. Software do tipo SIG (Sistema de Informações Geográficas) são as principais plataformas computacionais para o processamento de imagens, geração de representações vetoriais e armazenamento dos dados espaciais produzidos. Trabalhos como os relatados por Braga; Oliveira (2005), Rudorff; 
Moreira (2002) e Toledo et al. (2011) também demonstram o uso do geoprocessamento na análise espacial de áreas de produção agrícola com sistemas de irrigação.

Diante deste contexto, o presente trabalho tem como objetivo quantificar áreas irrigadas por pivôs centrais em três importantes regiões agrícolas no Estado de Mato Grosso, entre os anos de 2004 até 2015.

\section{MATERIAL E MÉTODOS}

A abordagem para a realização do presente trabalho consistiu na implementação de três etapas principais (Figura 1), tendo cada uma destas uma sequência de sub-rotinas específicas para que se pudesse avançar para a seguinte. Nos tópicos abaixo são apresentados as áreas de estudo e os detalhes da metodologia utilizada.

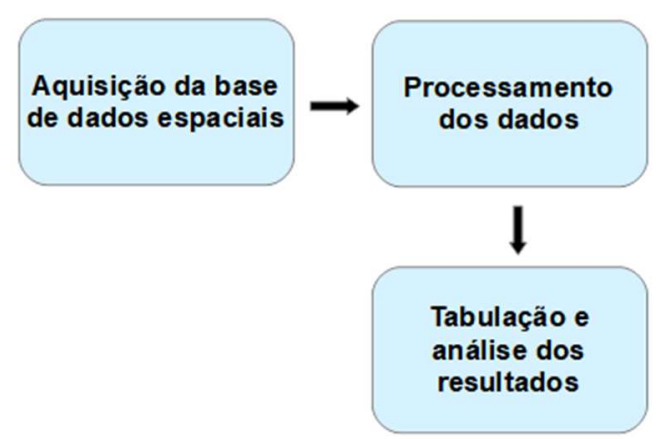

Figura 1. Fluxograma das etapas principais.

Figure 1. Flow chart of methodology main stages

\section{1. Área de Estudo}

Foram selecionadas 3 regiões que apresentam destaque na produção de grãos no Estado de Mato Grosso: região Médio Norte, região dos Parecis e região Sudeste. Estas áreas totalizam 19 municípios, os quais correspondem a área de 133.710,48 km². Na Figura 2 representa o mapa do Estado de Mato Grosso e a localização das respectivas áreas de estudo.

A primeira compreende a região Médio Norte do estado onde estão localizados os municípios de Cláudia, Ipiranga do Norte, Lucas do Rio Verde, Nova Mutum, Nova Ubiratã, Porto dos Gaúchos, Sinop, Sorriso, Tapurah e Vera, perfazendo área total de $60.977,6 \mathrm{~km}^{2}$.

A segunda área compreende a região dos Parecis, com os municípios de Brasnorte, Campo Novo do Parecis, Diamantino, São José do Rio Claro Sapezal. O território destes municípios totaliza o montante de $51.762,08 \mathrm{~km}^{2}$.

Já a última área, compreende a região Sudeste do estado, com os municípios de Campo Verde, General Carneiro, Poxoréo e Primavera do Leste, recobrindo uma área de $20.970,8 \mathrm{~km}^{2}$.

Segundo ANA (2019), das várias culturas agrícolas que fazem uso de pivôs centrais se destacam as culturas de canade-açúcar, algodão, café e, principalmente, soja, milho e feijão. Neste contexto, a escolha dos municípios se justifica por estes apresentarem grande participação no plantio e produção em algumas destas culturas, quando em comparação com o resto do estado. Juntos, esses municípios correspondem às seguintes porcentagens de área plantada e produção do Estado, respectivamente (IBGE, 2017):
- Soja: 49,47\% / 51,71\%

- Milho: $56,59 \% / 60,10 \%$

- Algodão: 73,44\% / 74,91\%

- Feijão: $75.80 / 80,47 \%$

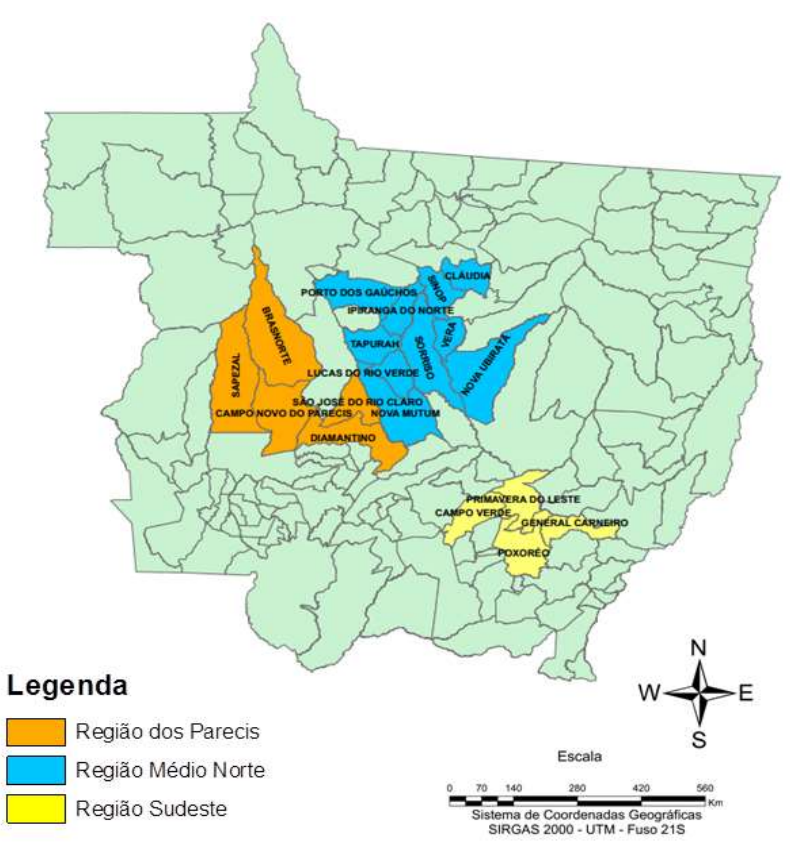

Figura 2. Mapa do Estado de Mato Grosso, com destaque para as áreas de estudo do trabalho. Fonte: Adaptado de Bobrzyk (2016). Figure 2. Map of the State of Mato Grosso, with emphasis on the work's study areas. Source: Adapted from Bobrzyk (2016).

\subsection{Aquisição dos dados espaciais}

Foram adquiridas imagens orbitais das áreas de estudo, para identificar e quantificar a ocorrência de pivôs centrais presentes em cada município. Para tanto, utilizou-se imagens dos satélites Resourcesat 1, Landsat 5, adquiridas no site do Instituto Nacional de Pesquisas Espaciais (INPE), e do satélite Landsat 8, adquiridas no site do Serviço de Levantamento Geológico Americano (USGS). Todas as imagens utilizadas são de livre acesso e distribuídas gratuitamente.

Foram utilizados três diferentes sensores orbitais devido à não continuidade de operação dos satélites ao longo do tempo avaliado. O Landsat 5 iniciou suas operações no ano de 1985, e teve sua missão finalizada em meados de 2011, sendo que o Resourcesat 1 foi lançado em órbita no ano de 2003 e ainda se encontra em operação nos dias atuais. Já o Landsat 8 iniciou suas operações no ano de 2013 e encontrase em operação atualmente (EMBRAPA, 2013).

Para a escolha das imagens levou-se em consideração a época relativa ao período seco das regiões de estudo, entre os meses de junho a setembro, quando há pouca presença de nuvens. Além disso, é no período seco em que há o maior uso de técnicas de irrigação.

$\mathrm{Na}$ Tabela 1 são representados quais sensores foram utilizados para cada ano analisado, assim como suas respectivas imagens identificas por suas órbitas-ponto. Os dados vetoriais utilizados representam os limites políticoadministrativos dos municípios mato-grossenses, os quais foram adquiridos gratuitamente através da base de dados espaciais do Instituto Brasileiro de Geografia e Estatística (IBGE). 
Tabela 1. Satélites e respectivas imagens utilizados para período de análise.

Table 1. Satellites and its images used for analysis on the period.

\begin{tabular}{|c|c|c|c|c|}
\hline \multirow{2}{*}{$\frac{\text { Satelite }}{\text { Periodo }}$} & \multirow{2}{*}{$\begin{array}{c}\text { LANDSAT } 5 \\
2004-2011\end{array}$} & \multicolumn{2}{|c|}{ RESOURCESAT 1} & LANDSAT 8 \\
\hline & & & & $2013-2015$ \\
\hline \multirow{10}{*}{$\begin{array}{l}\text { ÓRBITA } \\
\text { /PONTO }\end{array}$} & $224 / 71227 / 69$ & $317 / 84$ & $320 / 86$ & $224 / 71 \quad 226 / 69$ \\
\hline & $225 / 70 \quad 227 / 70$ & $317 / 85$ & $320 / 87$ & $225 / 70 \quad 226 / 70$ \\
\hline & $225 / 71 \quad 228 / 68$ & $317 / 86$ & $321 / 85$ & $225 / 71 \quad 226 / 71$ \\
\hline & $226 / 68 \quad 228 / 69$ & $317 / 87$ & $321 / 85$ & $226 / 68 \quad 227 / 68$ \\
\hline & $226 / 69228 / 70$ & $318 / 85$ & $321 / 86$ & \\
\hline & $226 / 70 \quad 229 / 69$ & $318 / 86$ & $321 / 88$ & \\
\hline & $226 / 71 \quad 229 / 70$ & $319 / 85$ & $322 / 87$ & \\
\hline & $227 / 68$ & $319 / 86$ & $322 / 88$ & \\
\hline & & $319 / 87$ & $323 / 88$ & \\
\hline & & $320 / 85$ & & \\
\hline
\end{tabular}

\subsection{Pré-processamento dos dados espaciais}

No fluxograma apresentado na Figura 3 estão representadas as etapas realizadas no pré-processamento dos dados espaciais adquiridos. Foram realizadas, de forma geral, composições coloridas das imagens orbitais selecionadas e posterior transformação dos seus respectivos sistemas de coordenadas.

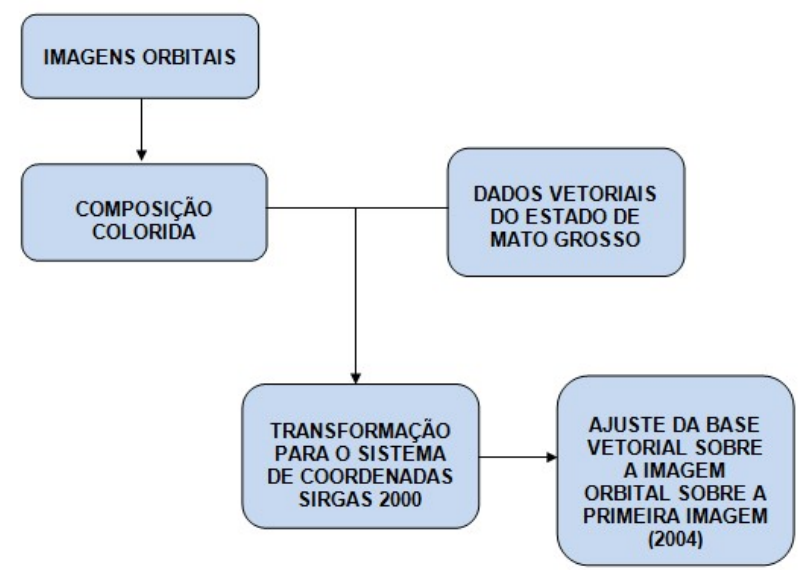

Figura 3. Etapas realizadas para o pré-processamento dos dados espaciais.

Figure 3. Steps for spatial data pre-processing.

$\mathrm{Na}$ etapa inicial do pré-processamento das imagens, foram adicionadas as bandas espectrais necessárias para fazer a composição colorida e os dados vetoriais do estado de Mato Grosso. Sendo que em relação às composições coloridas, trabalhou-se com a formatação falsa-cor para cada sensor utilizado: Landsat 5 - R5G4B3; RESOURCESAT R5G4B3; e LANDSAT 8 - R6G5B4.

$\mathrm{Na}$ Figura 4 é possível observar um exemplo dos resultados obtidos com o procedimento da composição colorida, referente ao satélite Landsat 8 , sendo as bandas 4 (região do vermelho), 5 (infravermelho próximo) e 6 (infravermelho médio) representadas pelas letras A, B e C, respectivamente, já a imagem $\mathrm{D}$ apresenta o resultado do processo de composição colorida. Posteriormente foram realizadas as transformações das projeções referentes às composições coloridas, geradas para cada ano de análise, a partir do sistema de coordenadas original das imagens (UTM - WGS84) para o sistema de coordenadas SIRGAS 2000.

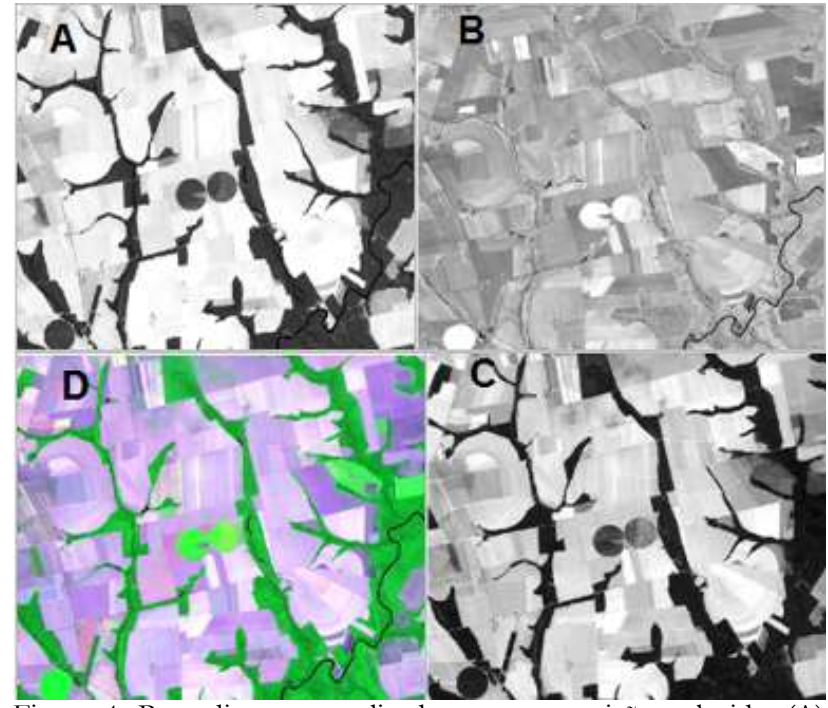

Figura 4. Procedimentos realizados na composição colorida. (A) banda 4, (B) banda 5, (C) banda 6 e (D) composição colorida falsa cor.

Figure 4. Composite bands procedure: band 4, band 5, band 6 and false color composite result.

Também se fez necessário proceder com o ajuste posicional (translação simples) da base vetorial sobre a imagem orbital, de forma a tornar todos os dados espaciais utilizados correlacionados posicionalmente entre si, principalmente em relação ao correto posicionamento dos limites territoriais dos municípios em relação às imagens orbitais (Figura 5)

$\mathrm{Na}$ Figura 5A está representada a imagem com a base vetorial, sendo que logo após a mesma ter sido exportada, pode-se observar que o posicionamento dos limites municipais não coincide com a imagem orbital. Tal fato gera a necessidade de ajustar a base vetorial sobre a imagem (Figura 5B).

\subsection{Processamento dos dados espaciais}

Nesta etapa foram executadas as ações de processamento dos dados espaciais com a finalidade de identificar e quantificar os pivôs de irrigação. Uma visão geral dos procedimentos desta etapa está apresentada na Figura 6. Já na Figura 7 é possível observar os pivôs presentes na imagem, sendo que a resposta espectral diferenciada na maioria dos pivôs também se mostra como uma característica que facilita a identificação dos mesmos.

Depois de finalizado o primeiro ano de análise, foi gerada uma cópia da layer (camada de informação no ambiente SIG) referente aos pivôs vetorizados, sendo exportada para uma nova layer associada ao ano de análise. Para que a mesma fosse atualizada com as informações da imagem do ano seguinte, sendo que esse processo foi repetido até o último ano de análise.

A partir da identificação visual dos pivôs é executada a sua vetorização (Figura 8), permitindo, assim, a identificação, localização espacial e o armazenamento dos dados gerados. $\mathrm{Na}$ Figura 9, demonstra-se o município de Sorriso no o ano de 2015, com os pivôs vetorizados do ano de 2014, os mesmos foram exportados para serem atualizados com a imagem de 2015 . 


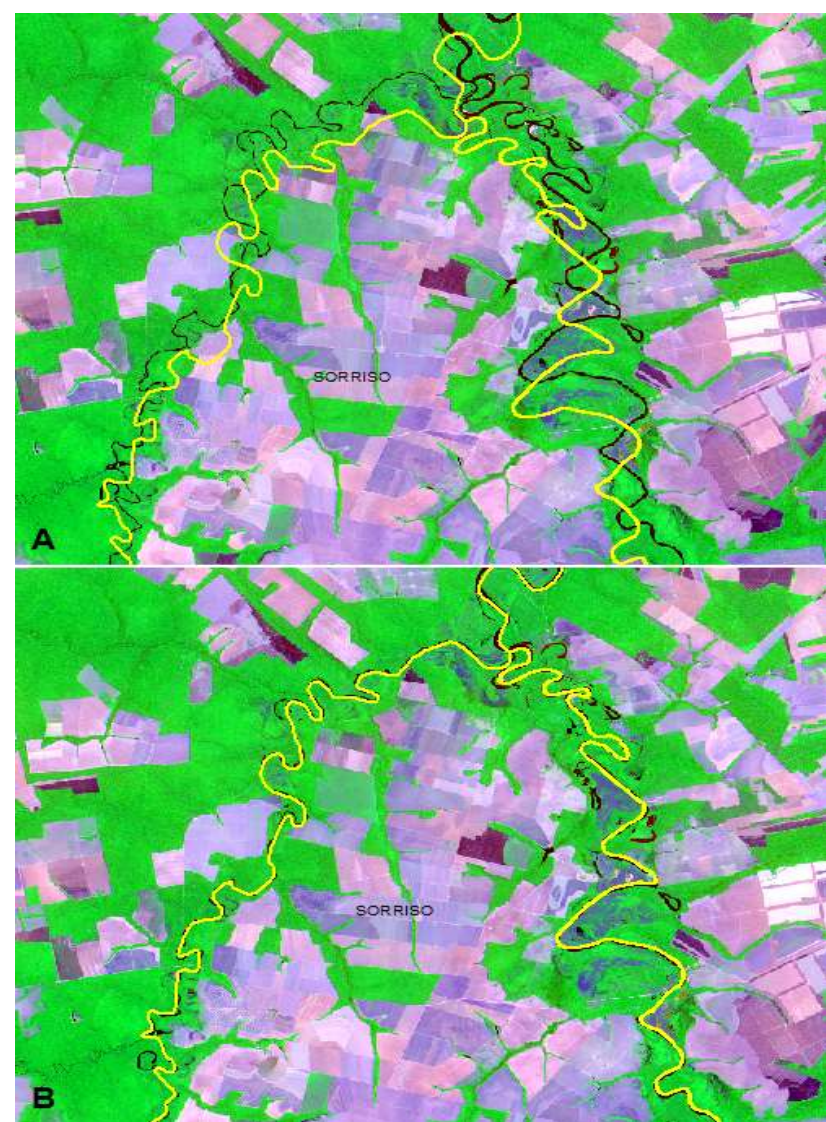

Figura 5. Ajuste da base vetorial sobre a imagem. (A) base vetorial não ajustada, (B) base vetorial ajustada.

Figure 5. Vector base adjustment based in image. (A) non-adjusted vetorial base, (B) adjusted vectorial base.

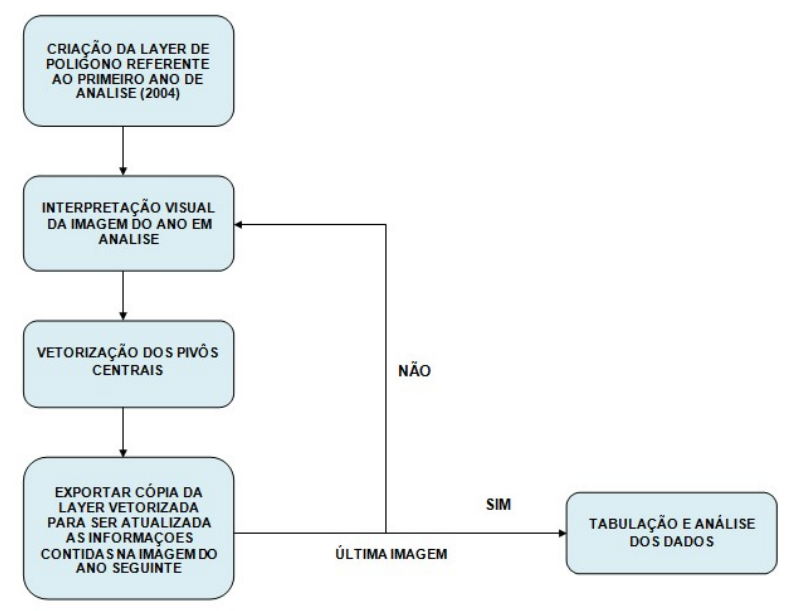

Figura 6. Etapas realizadas no processamento dos dados espaciais Figure 6. Steps of processing spatial data

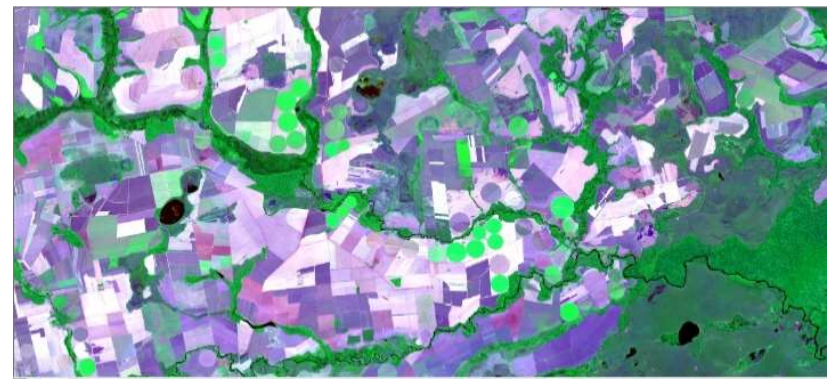

Figura 7. Imagem antes de passar pelo processo de vetorização. Figure 7. Image before vectorization process.

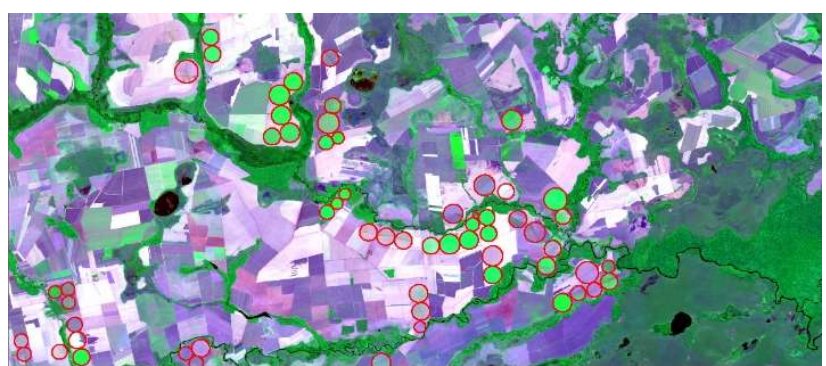

Figura 8. Imagem com os pivôs vetorizados.

Figure 8. Image with vectorized pivots.

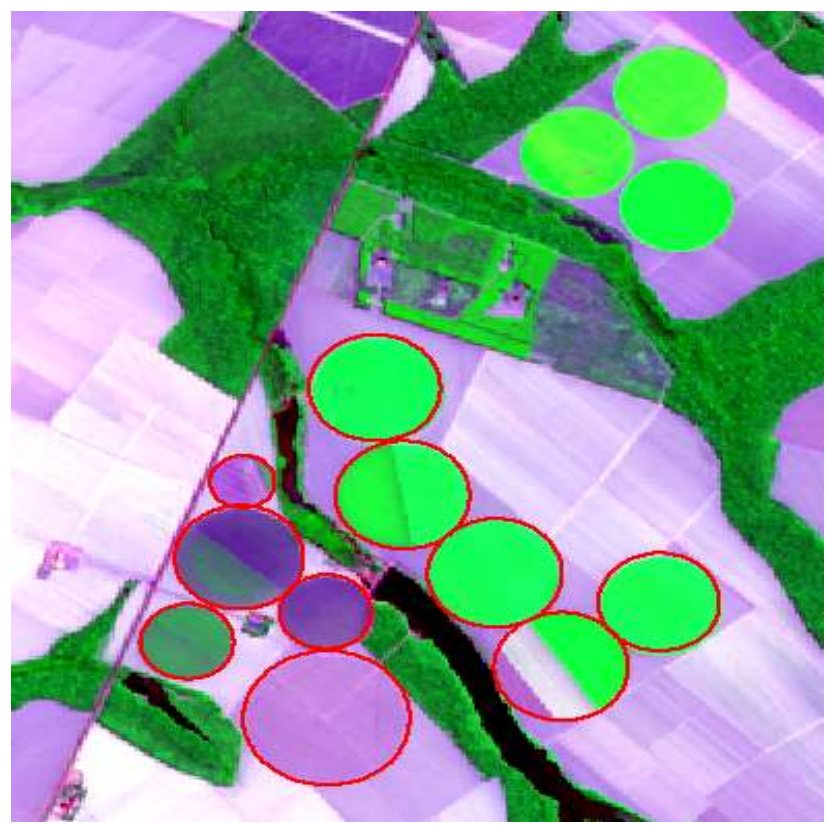

Figura 9. Exemplo da exportação dos dados vetoriais do ano de 2014 para a imagem de 2015.

Figure 9. Sample of vectorial data exportation from 2014 to 2015.

É interessante ressaltar que este procedimento de cópia dos dados vetorizados se mostrou eficaz para agilizar os trabalhos, pois era comum a ocorrência das novas áreas irrigadas identificas no ano anterior serem observadas no ano subsequente.

Com a finalização da etapa de vetorização dos pivôs centrais para toda área e período avaliados, foi iniciado o processo de análise/cálculo de informações de interesse nas tabelas de atributos geradas para cada elemento gráfico representativo.

$\mathrm{Na}$ tabela de atributos foram criadas colunas para a inserção dos valores referente ao cálculo de área, perímetro e raio de cada pivô. Deste modo, para cada ano foi quantificado o número de pivôs centrais e calculada a área de cada pivô, a área mínima, máxima, média e total de cada ano (em hectares).

Com o número de pivôs presentes em cada ano foi possível calcular a variação (em porcentagem) de ano para ano em cada município. Foi calculada também a variação (em porcentagem) da área total de ano para ano. A partir desses dados foi definida a média e o desvio padrão dos 11 anos de cada município através de planilha eletrônica.

\section{RESULTADOS}

As Tabelas 2 e 3 e as Figuras 10 e 11, apresentam, respectivamente, o número de pivôs centrais e o total de área 
irrigada por Região (Norte, Parecis e Sudeste), bem como a soma dos valores regionais e a variação percentual em relação ao ano anterior.

Tabela 2. Evolução do quantitativo de pivôs de irrigação entre os anos de 2004 a 2015 para as três regiões.

Table 2. Evolution of the number of irrigation pivots between the years 2004 to 2015 for the three regions.

\begin{tabular}{cccccc}
\hline Ano & $\begin{array}{c}\text { Região } \\
\text { Norte } \\
\text { (unid.) }\end{array}$ & $\begin{array}{c}\text { Região } \\
\text { dos } \\
\text { Parecis } \\
\text { (unid.) }\end{array}$ & $\begin{array}{c}\text { Região } \\
\text { Sudeste } \\
\text { (unid.) }\end{array}$ & $\begin{array}{c}\text { Total } \\
\text { (unid.) }\end{array}$ & $\begin{array}{c}\text { Variação } \\
\text { Anual (\%) }\end{array}$ \\
\hline 2004 & 93 & 42 & 124 & 259 & - \\
2005 & 101 & 44 & 132 & 277 & 6,95 \\
2006 & 97 & 43 & 135 & 275 & $-0,72$ \\
2007 & 95 & 40 & 127 & 262 & $-4,73$ \\
2008 & 102 & 45 & 127 & 274 & 4,58 \\
2009 & 103 & 45 & 138 & 286 & 4,38 \\
2010 & 106 & 42 & 141 & 289 & 1,05 \\
2011 & 111 & 42 & 147 & 300 & 3,81 \\
2012 & 135 & 46 & 155 & 336 & 12,00 \\
2013 & 199 & 56 & 175 & 430 & 27,98 \\
2014 & 234 & 59 & 209 & 502 & 16,74 \\
2015 & 284 & 65 & 237 & 586 & 16,73 \\
\hline Média & 138,333 & 47,417 & 153,917 & 339,667 & 8,07 \\
\hline Desvio & \multirow{2}{*}{64,285} & 8,005 & 35,717 & 107,529 & 9,47 \\
Padrão & & & & & \\
\hline
\end{tabular}

Tabela 3. Evolução de área total irrigada entre os anos de 2004 a 2015 para as três regiões analisadas.

Table 3. Evolution of total irrigate area between the years 2004 and 2005 for the three regions analyzed.

\begin{tabular}{cccccc}
\hline Ano & $\begin{array}{c}\text { Região } \\
\text { Norte } \\
\text { (ha) }\end{array}$ & $\begin{array}{c}\text { Região dos } \\
\text { Parecis } \\
\text { (ha) }\end{array}$ & $\begin{array}{c}\text { Região } \\
\text { Sudeste } \\
\text { (ha) }\end{array}$ & $\begin{array}{c}\text { Total } \\
\text { (ha) }\end{array}$ & $\begin{array}{c}\text { Variação } \\
\text { Anual (\%) }\end{array}$ \\
\hline 2004 & 11518,96 & $5.243,531$ & $15.302,594$ & $32.065,08$ & - \\
2005 & $12.428,352$ & $5.468,942$ & $16.351,241$ & $34.248,54$ & 6,81 \\
2006 & $11.985,748$ & $5.439,558$ & $16.771,263$ & $34.196,57$ & $-0,15$ \\
2007 & $11.790,476$ & $4.951,117$ & $15.970,217$ & $32.711,81$ & $-4,34$ \\
2008 & $12.716,231$ & $5.625,879$ & $16.015,922$ & $34.358,03$ & 5,03 \\
2009 & $12.969,425$ & $5.625,879$ & $17.182,112$ & $35.777,42$ & 4,13 \\
2010 & $13.152,545$ & $5.249,994$ & $17.570,350$ & $35.972,89$ & 0,55 \\
2011 & $13.816,383$ & $5.249,994$ & $18.328,387$ & $37.394,76$ & 3,95 \\
2012 & $16.858,701$ & $5.752,687$ & $19.245,620$ & $41.857,01$ & 11,93 \\
2013 & $25.742,600$ & $6.872,454$ & $21.794,023$ & $54.409,08$ & 29,99 \\
2014 & $29.836,156$ & $7.223,255$ & $26.552,124$ & $63.611,54$ & 16,91 \\
2015 & $35.488,884$ & $8.033,032$ & $30.628,850$ & $74.150,77$ & 16,57 \\
\hline Média & $17.358,705$ & $5.894,693$ & $19.309,392$ & $42.562,79$ & 8,31 \\
\hline Desvio & $8.225,641$ & 953,096 & 4753,190 & 13854,90 & 9,83 \\
Padrão & & & & & \\
\hline
\end{tabular}

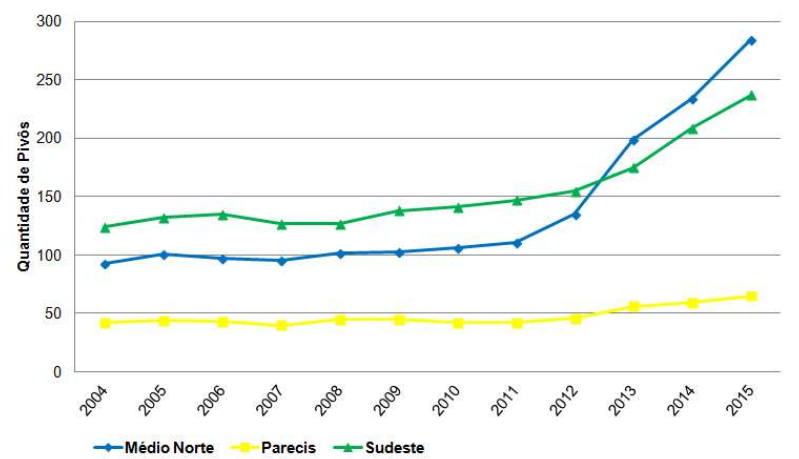

Figura 10. Dinâmica da evolução do quantitativo de pivôs em todas as regiões analisadas.

Figure 10. Dynamics of the evolution of the quantitative pivots in all regions analyzed.

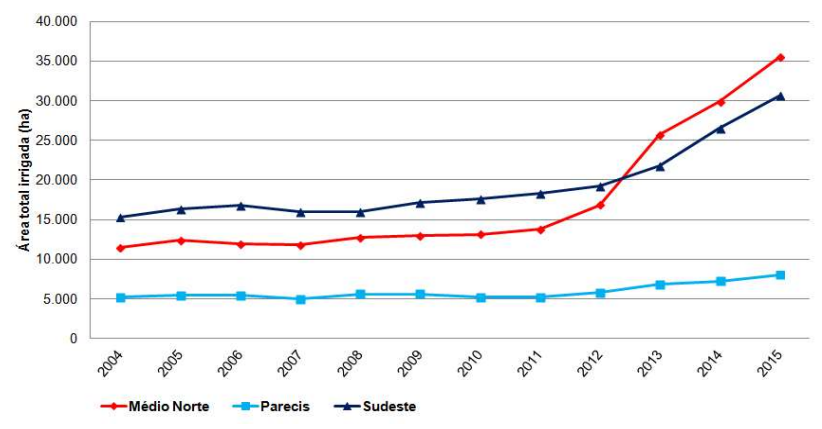

Figura 11. Evolução da área total irrigada durante os anos de 2004 até 2015 nas três regiões analisadas.

Figure 11. Evolution of the total irrigated area during the years 2004 to 2015 in the three regions analyzed.

\section{DISCUSSÃO}

De acordo com os números apresentados, pode-se observar que os anos de 2006 e 2007 apresentaram um decréscimo geral em relação aos anos anteriores, tanto na quantidade de pivôs centrais quanto em área irrigada. Entretanto, a Região Sudeste não apresentou decréscimo no ano de 2006 como as demais regiões, apenas no ano de 2007.

Os maiores incrementos nos valores encontrados ocorrem a partir de 2012. Entre os anos de 2008 a 2011 o crescimento médio do número de pivôs e área de irrigação por ano era em torno de 3,5\% e 3,4\%, respectivamente. Já no período entre 2012 e 2015 o crescimento anual salta para, em média, 18,4\% de pivôs centrais e 18,9\% de áreas irrigadas.

$\mathrm{Na}$ região Médio Norte o município que mais se destacou foi o de Sorriso (Figura 12), abrangendo 41\% do total de pivôs e 42,8\% de área irrigada, sendo o principal responsável pelo crescimento dessas variáveis nessa região. Isto se deve pelo fato deste município ser composto, em sua maioria, por grandes propriedades rurais com relevo propício à mecanização e implementação de sistemas de irrigação. Sorriso se destaca na produção de várias commodities, sendo responsável pelos seguintes valores da produção estadual (safra 2015/2016) de 6,74\% da soja, $11,96 \%$ do milho e $17,02 \%$ do feijão (IBGE, 2018).

Esta sazonalidade entre períodos antes e após 2012, pode ser atribuída crise financeira global que se iniciou entre 2007 e 2008. No ano de 2010 várias economias apresentaram altas taxas de crescimento econômico, tendo país deste processo de recuperação a China, provocando uma retomada nos preços das commodities (APEX-BRASIL, 2011).

O aumento do crédito rural também pode ser um fator a ser considerado no entendimento da expansão de sistemas de irrigação, visto que os mesmos exigem grandes investimentos financeiros. Segundo IPEA (2017) o Brasil passou de um volume financeiro aplicado ao crédito rural da ordem de 41,42 bilhões de reais em 2000, para um o valor de 154,14 bilhões em 2015, sendo que para este ano o valor médio dos contratos de crédito agrícola no Estado de Mato Grosso ficou por volta de 210 mil reais (não especificando os usos específicos destes recursos).

A causalidade entre as variáveis se torna evidentes na similaridade do padrão das curvas de crescimento de número de pivôs e áreas irrigadas para as três regiões, conforme mostram os gráficos. A maior alta ocorre, no geral, no ano de 2013. Entretanto a Região Sudeste se apresenta novamente como exceção, pois sua maior alta ocorre em 2014. 


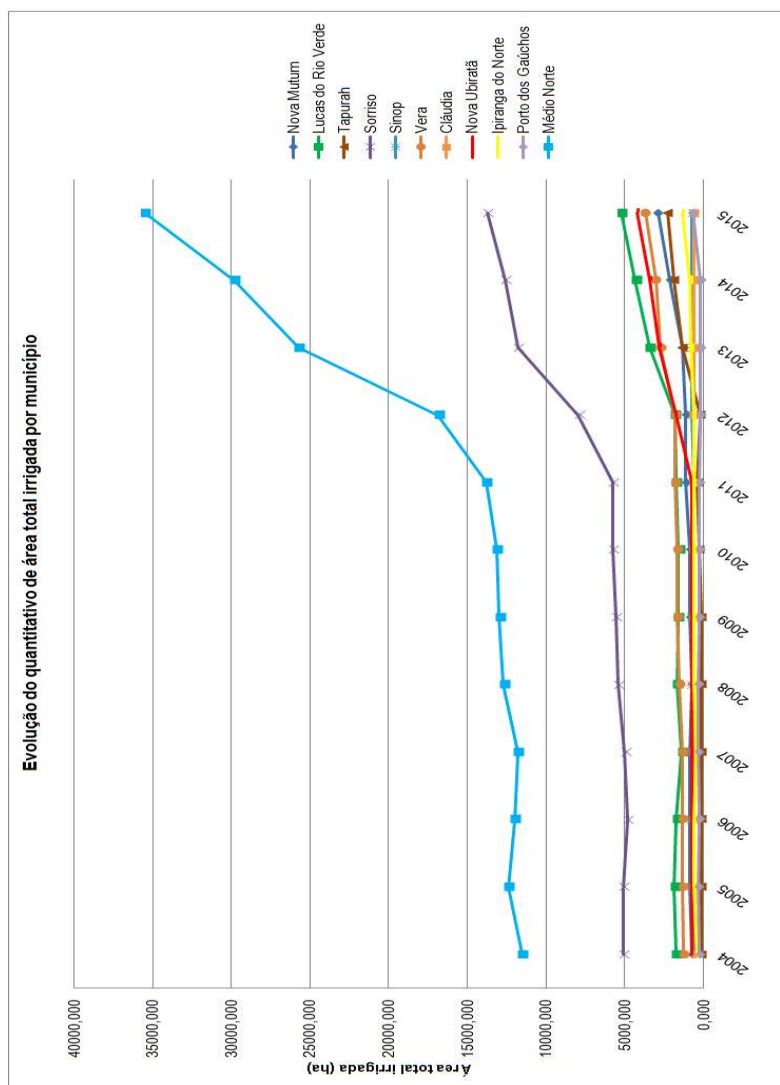

Figura 12. Evolução de cada município e dos dados gerais em relação à área total irrigada na região Médio Norte.

Figure 12. Evolution of each municipality and of the general data in relation to the total irrigated area in the Middle North region.

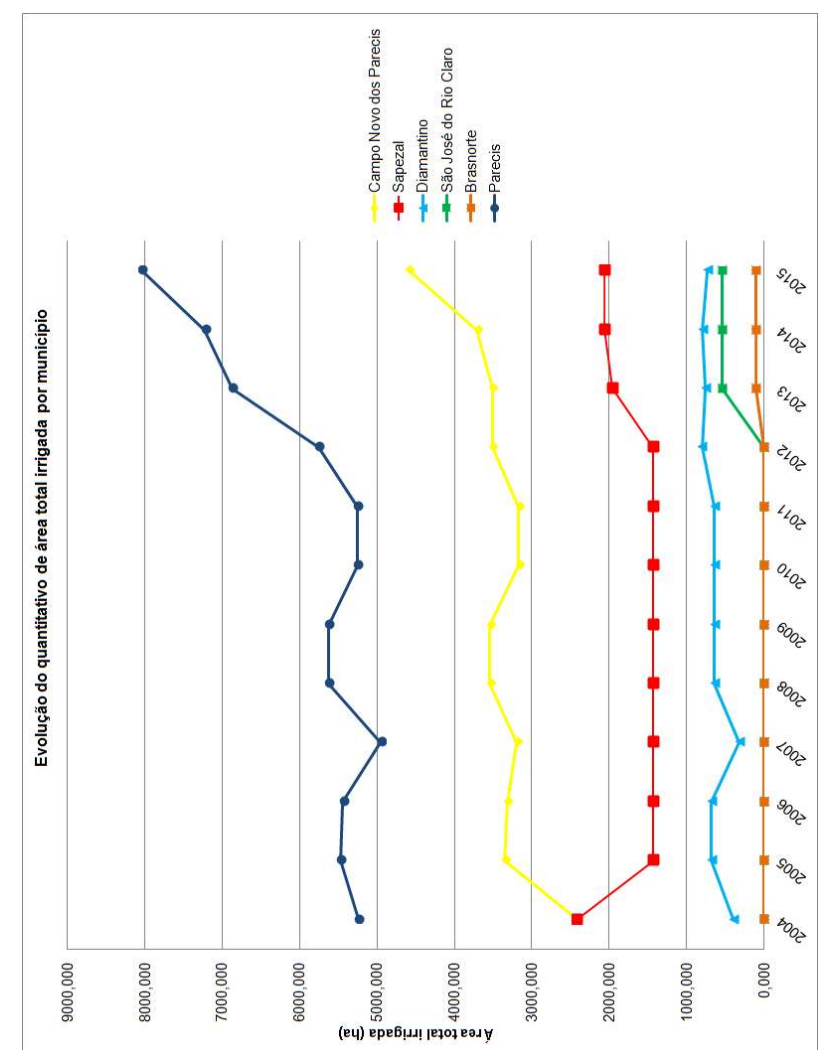

Figura 13. Distribuição dos municípios e dos dados gerais em relação à área total irrigada na região dos Parecis.

Figure 13. Distribution of municipalities and general data in relation to the total irrigated area in the Parecis region.

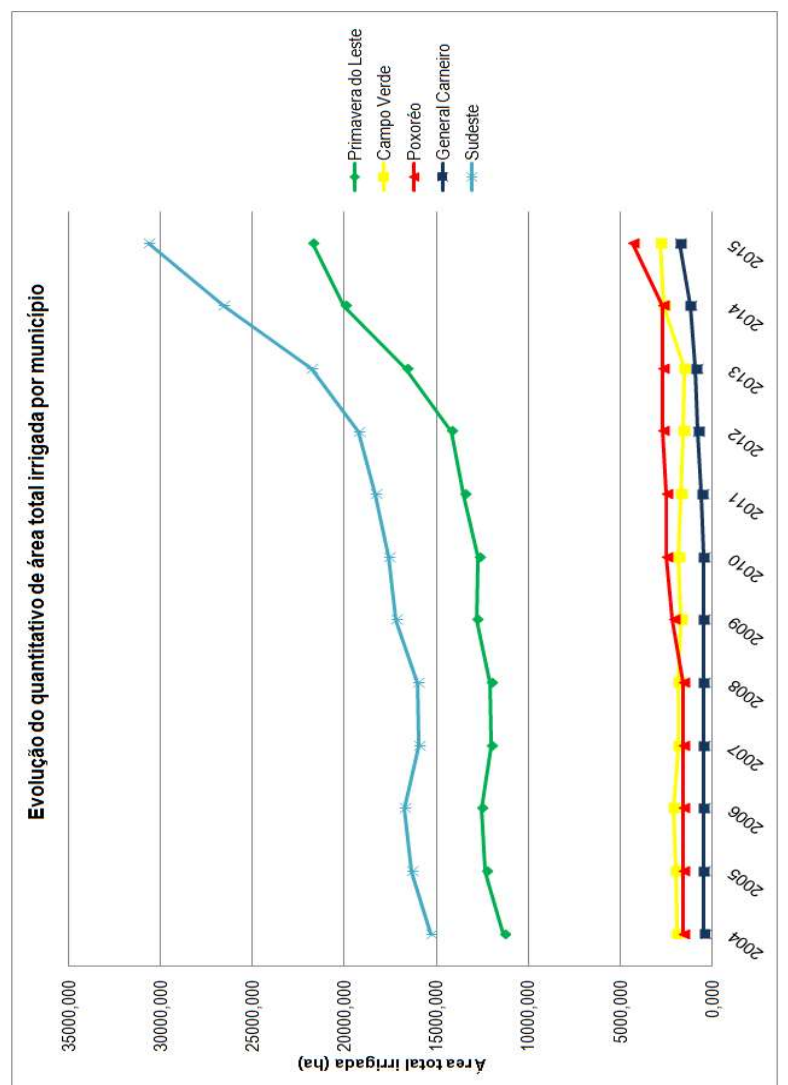

Figura 14. Distribuição dos municípios e dos dados gerais em relação à área total irrigada na região Sudeste.

Figure 14. Distribution of municipalities and general data in relation to the total irrigated area in the Southeast region.

O crescimento do uso de pivôs de irrigação nas regiões estudadas foi da ordem de $231,25 \%$ para o período de 2004 até 2015 , valor muito superior à média brasileira, que foi de $59,09 \%$, conforme apresentado por IBGE (2019) considerando o recorte temporal de 2006 até 2017. Já os dados apresentados por ANA (2019) apontam para um crescimento, entre os anos de 2006 e 2016, de 66,18\% para sistemas de irrigação (todos os tipos) em território brasileiro, sendo que para o ano de 2015 foi verificado que do total de áreas irrigadas $20 \%$ aplicavam sistemas por pivô central.

Observa-se que a curva de crescimento da região dos Parecis se mantém nos valores mais baixos e apresenta um incremento menos significativo em relação às demais regiões, totalizando um acréscimo de $54,8 \%$ dos pivôs e $53,2 \%$ de hectares de área irrigada ao longo dos 11 anos analisados.

Em comparação à região Sudeste, esta apresentou 91,1\% de crescimento no número de pivôs e $100,2 \%$ de crescimento em hectares de área irrigada. Porém o maior crescimento foi identificado na região Médio-Norte, alcançando um aumento de pivôs em $205,4^{\circ}$ e e de 208,1\% de hectares de área irrigada

Além disso, é possível identificar com mais facilidade nos gráficos os dois períodos distintos: entre 2004 e 2011, no qual a evolução dos quantitativos é, no geral positiva, porem pequena; e entre 2012 e 2015, no qual verifica-se um crescimento substancial das irrigações por pivô central.

No ano de 2015, as três regiões apresentavam, juntas, $74.150,77$ hectares de área irrigados por 586 pivôs, o que resulta em uma média de 126,54 hectares abrangidos por cada pivô de irrigação. 
Na região dos Parecis foram analisados os municípios de Brasnorte, Campo Novo do Parecis, Diamantino, São José do Rio Claro e Sapezal (Figura 13). Campo Novo do Parecis foi o município destaque desta região, correspondendo a $55,3 \%$ do total de pivôs instalados e $58,3 \%$ da área total irrigada da região.

Já na região Sudeste (Figura 14) foram analisados apenas quatro municípios: Campo Verde, General Carneiro, Poxoréo e Primavera do Leste, sendo este o que se destacou. Em relação à região em que está inserido, Primavera do Leste corresponde, em média, a 76,6\% dos pivôs instalados, e $74,4 \%$ da área total irrigada. Com isto, evidencia o alto peso que o município tem na região analisada.

O fato de um município se destacar em cada região se mostrou um padrão em todas as regiões, visto se tratar de municípios com um perfil de propriedades rurais com grandes extensões e voltadas às culturas extensivas, as quais se destacam por uma maior capacidade de investimento na implementação de sistemas de irrigação por pivôs centrais.

As regiões dos Parecis e Sudeste apresentam uma menor diferença na totalidade de áreas irrigadas entre o primeiro e segundo colocado, diferentemente da região Médio Norte onde o município de Sorriso apresenta uma posição de destaque em relação à sua região. Ainda no caso de Sorriso, e também diferentemente das outras regiões, o mesmo não é cidade polo, administrativamente, cabendo ao município Sinop este papel.

Entretanto Sinop não apresenta o mesmo perfil de propriedades rurais, apresentando um número maior de médias e pequenas propriedades, as quais não fazem uso de sistemas extensivos de irrigação.

\section{CONCLUSÕES E RECOMENDAÇÕES}

Áreas irrigadas demandam grandes quantidades de água de modo a intensificar a captação de mananciais superficiais e subterrâneos. Desta forma, uma gestão eficiente dos recursos hídricos passa, necessariamente, pela compreensão da distribuição espacial e temporal dessa atividade no território.

Dados levantados pelo Censo Agropecuário de 2006 (IBGE, 2009) totalizavam, no ano de 2006, um montante de 45 pivôs inseridos nas áreas analisadas, perfazendo uma área total de 10.000 hectares. Os resultados obtidos mostraram que em 2006, somente nas três regiões de estudo, a área total irrigada por pivô central era de 34.196,57 hectares e o número de pivôs encontrados foi de 275 , ou seja, maior do que a levantada pelo censo para o Estado.

Ao compararmos estes valores com os dados obtidos neste trabalho, tem-se uma variação de 511,11\% e 241,90\%, respectivamente em relação ao quantitativo de pivôs e o total e áreas. A grande diferença entre os resultados pode ser explicada pela diferença de metodologia para a aquisição destes valores nos dois estudos.

O Censo Agropecuário investiga os estabelecimentos agropecuários e as atividades neles desenvolvidas, obtendo informações sobre as características do produtor e do estabelecimento, bem como sobre a economia e o emprego no meio rural, no que diz respeito à agricultura, pecuária e agroindústria. Sendo esse processo realizado, basicamente, através de pesquisas em sindicatos rurais e entrevistas com os produtores (IBGE, 2009).
Outra fonte de informações que foi utilizada para comparar os resultados obtidos neste trabalho, refere-se ao estudo realizado pela ANA e EMBRAPA para o ano de 2014, sobre áreas irrigadas por pivô central. Este levantamento mostrou que para os mesmos municípios analisados no presente trabalho o total de pivôs encontrados foi de 538 e a área total irrigada foi de 66.161 hectares. Já os dados obtidos neste trabalho demonstram um total de 502 pivôs e um total de área irrigada com aproximadamente 63.611 hectares. Neste caso, a diferença entre os levantamentos $-6,69 \%$ para o quantitativo de pivôs e de $-3,85 \%$ para a área total irrigada.

Explicações para a evolução da irrigação por pivô ao longo dos anos, de maneira precisa, se mostra uma tarefa extremamente difícil devido a extensa área estudada e a grande quantidade propriedades rurais. Fatores como valorização, ou não, das commodities, variação na taxa de câmbio (o que impacta substancialmente tanto a venda de commodities quanto a aquisição de insumos), restrições ambientais, alto custo na aquisição de novas visando o incremento da produção agrícola e condições físicoambientais, podem impactar a decisão de se implantar um qualquer tipo de sistema de irrigação.

Deste modo, uma análise macro que ajude a entender a dinâmica do uso de pivôs centrais se torna mais relevante para o que se propõem o presente trabalho, o qual é propiciar dados quantitativos que possam subsidiar novas pesquisas relacionando os fatores acima citados.

Enquanto fatores físicos balizam a aptidão de uma determinada área para o uso de sistemas de irrigação, aspectos socioeconômicos, influenciam na decisão de implantação destes sistemas. No tocante aos aspectos físicos, as regiões analisadas apresentam, em boa parte de seus territórios, condições ambientais propícias para a uso da irrigação na produção agrícola, tanto no tocante ao relevo como na oferta de recursos hídricos.

Dentre as três regiões analisadas, a região Sudeste foi a que apresentou o maior crescimento no período de estudo, perfazendo uma taxa média anual no quantitativo de pivôs de $46,20 \%$, sendo que a área total irrigada apresentou um crescimento médio anual de 46,24\%. Em seguida, a região Médio Norte, com um incremento médio anual de 39,36\% no quantitativo de pivôs, e 39,37\% no que se refere à área total irrigada. Já a região dos Parecis apresentou valores da ordem de $14,44 \%$ e $14,39 \%$, para pivôs e área total irrigada, respectivamente.

As análises mostraram que ao longo do período de estudo houve uma troca de posições em relação ao quantitativo de pivôs e área total irrigada, pois em 2004 a região Sudeste apresentava os maiores percentuais de área total irrigada e de pivôs, respectivamente $47,72 \%$ e $47,88 \%$, porém, a partir do ano de 2013, a região Médio Norte passou a apresentar maiores percentuais de pivôs e área total irrigada, perfazendo $46,28 \%$ e $47,31 \%$, respectivamente.

Em relação ao quantitativo de pivôs e área total irrigada, em todas as regiões, as variações médias proporcionaram a identificação de dois períodos distintos de evolução: i) entre os anos de 2004 a 2011, as variações médias foram de aproximadamente $2,0 \%$ para as três regiões; ii) já no período de 2012 até 2015 houve um crescimento considerável, apresentando médias de aproximadamente $18,0 \%$, tanto para quantitativo de pivôs, quanto para área total irrigada. 
Para trabalhos futuros na área, alguns pontos podem ser abordados para evoluir no entendimento da dinâmica dos pivôs centrais, assim como avaliar fatores que corroborem com sua ocorrência. Em relação à espacialidade dos pivôs, sugere-se relacioná-los com as bacias hidrográficas em que se encontram, de modo a propiciar análises que permitam identificar os impactos no ambiente em relação ao consumo de água. Também este relacionamento espacial com as bacias poderia gerar informações voltadas para planejamento/gestão de outorgas para o uso da água junto aos órgãos públicos responsáveis.

As opções de estudo em relação aos fatores que interferem no processo de decisão da implantação dos sistemas de irrigação, propiciam linhas de pesquisa que podem ser abordados, tais como a relação com a demanda por novas áreas, visando o incremento da produtividade agrícola, que por sua vez tem suas bases na demanda por commodities, principalmente do mercado externo. Análises econômicas mais detalhadas de forma a avaliar as variações monetárias decorrentes das demandas por produtos agrícolas frente à evolução no uso de pivôs. Um estudo interessante foi realizado por Klemp (2010) no qual a autora aborda a correlação entre produto interno bruto brasileiro e variações na taxa de câmbio com a dinâmica espacial de pivôs centrais de irrigação na bacia do Alto Rio das Mortes-MT ao longo de um recorte temporal de aproximadamente 20 anos.

Por fim, sugere-se uma análise de mercado que avalie o custo benefício da implantação de pivôs, visando o aumento da produtividade de uma determinada cultura agrícola, frente à opção de aquisição de novas áreas para propiciar este aumento no volume produzido.

\section{REFERÊNCIAS}

ANA_Agência Nacional de Águas. Levantamento da Agricultura Irrigada por Pivôs Centrais no Brasil 2014: Relatório Síntese. Brasília, DF, 2016. 33p.

ANA/EMBRAPA/CNPMS_Agência Nacional de Águas \& Empresa Brasileira de Pesquisa Agropecuária. Levantamento da Agricultura Irrigada por Pivôs Centrais no Brasil (1985-2017). Brasília, 2019. 49p. Disponível em: http://arquivos.ana.gov.br/imprensa/arquivos/Projeto Pivos.pdf/. Acesso em: 01/07/2019.

ANA/EMBRAPA/CNPMS_Agência Nacional de Águas \& Empresa Brasileira de Pesquisa Agropecuária. Levantamento da Agricultura Irrigada por Pivôs Centrais no Brasil - ano 2014. Disponível em: http://metadados.ana.gov.br/geonetwork/. Acesso em: 12/05/2016.
APEX-BRASIL_Agência Brasileira de Promoção de Exportações e Investimentos. As Exportações Brasileiras e os Ciclos de Commodities: tendências recentes e perspectivas. Brasília, 2011. 61p.

BRAGA, A. L.; OLIVEIRA, J. C. Identificação e quantificação de áreas irrigadas por pivô central utilizando imagens CCD/CBERS. In: XII Simpósio Brasileiro de Sensoriamento Remoto, Goiânia. Anais... INPE, p. 849-856, 2005.

BOBRZYK, L. D. Analise Espaço-Temporal do uso de pivôs de irrigação em regiões agrícolas no estado de Mato Grosso. 2016. 85 f. Monografia (Graduação em Engenharia Agrícola e Ambiental) - Instituto de Ciências Agrárias e Ambientais, Universidade Federal de Mato Grosso, Sinop.

EMBRAPA_Empresa Brasileira de Pesquisa Agropecuária. Satélites de Monitoramento. Campinas: Embrapa Monitoramento por Satélite, 2013. Disponível em: http://www.sat.cnpm.embrapa.br. Acesso em: 06/07/2018.

IBGE_Instituto Brasileiro de Geografia e Estatística. Censo Agropecuário 2006. Rio de Janeiro, 2009.

IBGE_Instituto Brasileiro de Geografia e Estatística. Produção Agrícola Municipal - Culturas Temporárias e Permanentes (2016). Rio de Janeiro, 2017. 64p. Disponível em: https://biblioteca.ibge.gov.br/visualizacao/periodicos/ 66/pam_2016_v43_br.pdf. Acesso em: 01/12/2019.

IPEA_Instituto de Pesquisa Econômica Aplicada. Boletim Regional, Urbano e Ambiental. Brasília, 2017. 12p.

KLEMP, S. M. Análise espaço-temporal de pivôs de irrigação central, na Bacia Hidrográfica do Alto Rio das Mortes - MT. 2010. 79p. Dissertação de Mestrado. Pós-Graduação em Recursos Hídricos - Universidade Federal de Mato Grosso, Cuiabá. 2010.

MANTOVANI, E. C.; BERNARDO, S.; PALARETTI, L. F. Irrigação: princípios e métodos. 2 ed. Viçosa: UFV, 2007. 358 p.

RUDORFF, B. F. T.; MOREIRA, M. A. Sensoriamento Remoto aplicado á agricultura. São José dos Campos: INPE, 2002. 20p. Disponível em: <http://mtcm12.sid.inpe.br/col/sid.inpe.br/sergio/2005/06.14.13.1 4/doc/CAP9_MAMoreira.pdf>. Acesso em: 13/04/2019.

TOLEDO, J. H.; FERREIRA, E; DANTAS, A. A. A.; SILVA, L. S. C.; PEREIRA, R. M. Mapeamento de sistemas de pivôs centrais no Estado de Minas Gerais a partir de imagens CBERS-2B/CCD. In: XV Simpósio Brasileiro de Sensoriamento Remoto, Curitiba. Anais... INPE, p.0331, 2011. 